\title{
Óscar Miguel Aguirre Jáuregui (1939-2017)
}

\author{
Guillermo Yanowsky-Reyes and Jaime Nieto-Zermeño* \\ Dirección Médica, Hospital Infantil de México Federico Gómez, Mexico City, Mexico
}

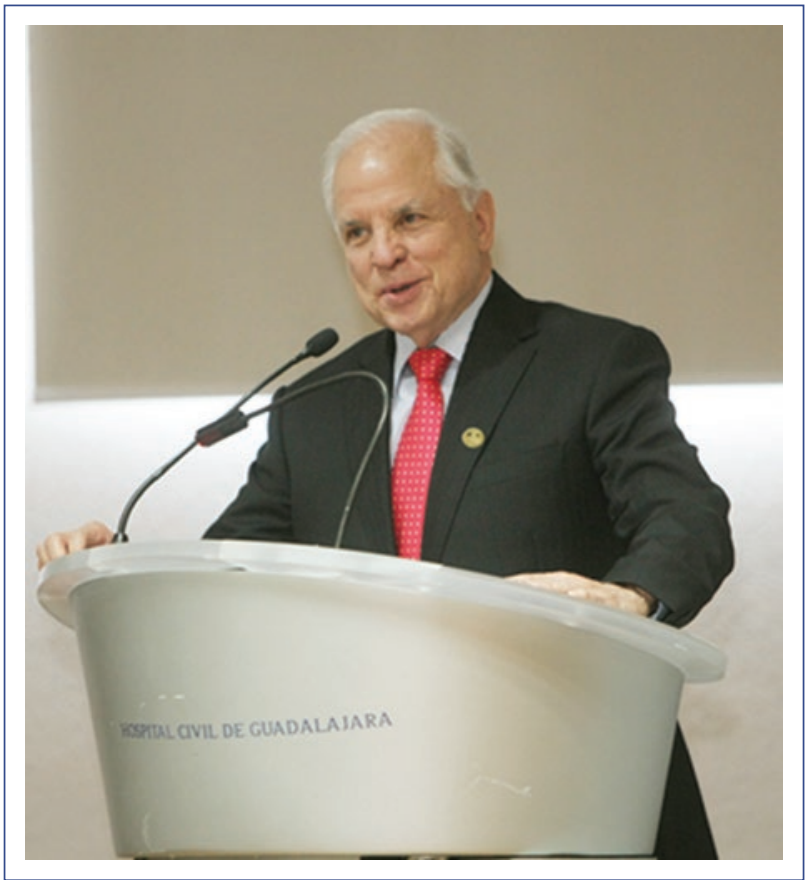

On September 14, 2017, Dr. Óscar Miguel Aguirre Jáuregui passed away. He was a distinguished graduate of the Hospital Infantil de México Federico Gómez, leader of Pediatric Surgery and Endoscopy in the state of Jalisco and professor at the Universidad de Guadalajara.

Doctor by the Universidad de Guadalajara (1957/1963), he specialized in Pediatrics (1962/1965) and Pediatric Surgery at the Hospital Infantil de México Federico Gómez (1966/1969), Fellowship in Pediatric Surgery at The Hospital for Sick Children, in London (1969/1970). He was Head of Service for 46 years and founding member of the Society of Pediatric Surgery of the West, the College of Pediatric Surgery of Jalisco, the Mexican College of Pediatric Surgery, President of the College of Pediatrics of Jalisco, professor of Pediatrics by the University of Guadalajara since 1970 and until his passing away. He also served as Professor of Pediatric Surgery at the Old Civil Hospital of Guadalajara (U de G) from 1986 to 2017, Principal Investigator C of the CUCS, U de G. He was director of the Old Civil Hospital of Guadalajara (1995-2001), Professor Pediatric Surgery Synod of the Mexican Council of Pediatric Surgery (1993), member of the Mexican Academy of Pediatrics

\section{Correspondence:}

*Jaime Nieto-Zermeño

Email: jnieto@ @imfg.edu.mx
Date of reception: 08-01-2018

Date of acceptance: 08-01-2018

DOI: 10.24875/BMHIME.M18000018
Available online: 12-07-2018 Bol Med Hosp Infant Mex. 2018;75:53-54

www.bmhim.com

22444-3409/C 2018. Hospital Infantil de México Federico Gómez, published by Permanyer México SA de CV, all rights reserved. 
(2013), Technical Secretary of the Multidisciplinary Group of Attention to the Abused Child in the Old Civil Hospital of Guadalajara since 1994. He was the author of great publications on Pediatric Surgery in international and national journals, author of book chapters, as well as hundreds of papers in congresses. He received several awards, such as Federico Gómez (1992), the Surgeon of Excellence, Hospital Infantil de México Federico Gómez (1996), as National Professor of the Mexican College of Pediatric Surgery, among other distinctions both professionally, socially and family related.

Dr. Aguirre Jáuregui was one of the pioneers of surgical pathology in children and teenagers in the west of the country, outstanding academic, scientist and teacher trainer of multiple generations of Pediatric Surgeons, excellent person, enthusiast and selfless driving forcé of young people who surrounded him.

He defined himself as a "hospital mouse" since he enjoyed his stay in the hospital and the service, sharing his experiences and new ideas. His passion was pediatric bronchoesophagology, which he learned at the Hospital Infantil de México and during his stay in
England. He quickly applied and consolidated it as a whole unit. He attended more than 500 cases in this unit, which provides service 365 days a year, 24 hours a day.

He had a large number of friends, of whom there was always a great interest in a fine, educated and sincere conversation, sometimes accompanied by excellent food and always an intelligent comment.

His family was of great value to him: his wife, Gloria, and their children, Gloria, Ceci, Óscar and Daniel, were his pride, as were his grandchildren. He always mentioned that he was a lucky man because of the family he had.

Finally, we wish to highlight and mention with pride that "the service sheet of Dr. Óscar Miguel Aguirre Jáuregui is complete", and we can say with confidence: "Mission accomplished. Good job, Master!" As an infinite thank you to his work, his family and his friends, these lines try modestly to describe his career and the feelings that, for sure, his colleagues in the Pediatric Surgery Service, his alumni and students share. Thank you very much for everything, Master. 